\title{
Do medical emergency teams improve the outcomes of in-hospital patients?
}

Hillman K, Chen J, Cretikos M, Bellomo R, Brown D, Doig G, et al.; MERIT study investigators. Introduction of the medical emergency team (MET) system: a cluster-randomised controlled trial. Lancet 2005;365(9477):2091-7.

Background: The goals of a medical emergency team (MET) are the early identification and treatment of potentially unstable conditions among in-hospital patients so that unexpected cardiac arrests, deaths, and unplanned intensive care unit (ICU) admissions may be prevented. The team usually consists of a physician, nurse and respiratory therapist skilled at critical and emergency care. A number of studies have shown an association between MET system implementation and decreased morbidity and mortality, but those studies have been of limited size and methodological rigour. ${ }^{1}$ Despite widespread implementation of METs, it is still unclear whether they lead to improved patient outcomes.

Design: In this cluster-randomized controlled trial, public hospitals in Australia with emergency and critical care services and more than 20000 annual admissions were assigned to receive a standardized MET implementation program or to continue usual care. A 2-month baseline observation period was followed by a 4-month education and implementation strat- egy for all hospitals receiving METs. Outcomes were measured during the following 6 months. The primary outcome was a composite measure of the incidence of unplanned ICU admissions, cardiac arrests, and unexpected deaths (without a pre-existing not-for-resuscitation order). Secondary outcomes included each of these events individually. The MET calling criteria consisted of disorders of breathing (respiratory rate $<5$ or $>36$ breaths per minute or respiratory arrest), circulation (pulse rate $<40$ or $>140$ beats per minute, systolic blood pressure $<90 \mathrm{~mm} \mathrm{Hg}$, or cardiac arrest), neurology (sudden fall in Glasgow coma scale $>2$ points or repeated or extended seizures) or "serious worry" about any patient.

Results: Of 23 hospitals enrolled in the study, 12 received MET systems and 11 provided usual care. All of the hospitals and their patients had similar characteristics and incidences of outcomes during the baseline period. The MET hospitals received more calls for emergency assessment than did the cardiac arrest teams of control hospitals.
METs were mobilized for $95 \%$ of patients who experienced unanticipated cardiac arrests and who fulfilled calling criteria but for only $8 \%$ of other unexpected deaths and only $30 \%$ of all patients admitted to the ICU. There were no significant differences in the combined or individual rates of cardiac arrest, unplanned ICU admissions and unexpected deaths between the 2 groups (Table 1), yet the combined incidence of events in both the MET and control hospitals decreased significantly between the baseline and study periods.

Commentary: This study is the largest and most robust randomized controlled trial to evaluate the effect of a dedicated MET or outreach system. Why did highly skilled teams who reacted promptly to liberal calling criteria not effect a change in the measured patient outcomes? First, although 23 hospitals participated, the study may yet have been underpowered to detect a difference. Second, only a minority of patients who fulfilled calling criteria were actually referred to the MET. It is possible that more sensitive criteria, more frequent patient assessments, or more advanced monitoring of patients would identify a greater number of patients at risk who might then derive benefit from a MET. It is also possi-

Table 1: Incidence rates of the primary and secondary outcomes in hospitals with and without METs during the study period*

\begin{tabular}{|c|c|c|c|c|}
\hline \multirow[b]{2}{*}{ Outcome } & \multicolumn{2}{|c|}{$\begin{array}{l}\text { Hospitals; crude rate } \\
\text { per } 1000 \text { patients }\end{array}$} & \multirow[b]{2}{*}{$p$ value } & \multirow[b]{2}{*}{ Difference $(95 \% \mathrm{Cl})$} \\
\hline & Without METs & With METs & & \\
\hline Primary outcome $†$ & 5.86 & 5.31 & 0.804 & $-0.264(-2.449$ to 1.921$)$ \\
\hline Cardiac arrest & 1.64 & 1.31 & 0.306 & $-0.208(-0.620$ to 0.204$)$ \\
\hline Unplanned ICU admission & 4.68 & 4.19 & 0.899 & -0.135 ( -2.330 to 2.060$)$ \\
\hline Unexpected death & 1.18 & 1.06 & 0.564 & $-0.093(-0.423$ to 0.237$)$ \\
\hline
\end{tabular}

Note: $\mathrm{MET}=$ medical emergency team, $\mathrm{Cl}=$ confidence interval, $\mathrm{ICU}=$ intensive care unit.

*Adapted with permission from Elsevier (Lancet 2005;365 [9477]:2091-7).

†The primary outcome was the composite of cardiac arrest, unplanned ICU admission and unexpected death. 
Practice

ble that the perceived benefits of the MET might not have been captured in the outcome measures chosen; patient satisfaction, quality of emergency and endof-life care, and hospital staff comfort were not measured.

Practice implications: In a health care system challenged by limited critical care resources, the notion of increased "pre-emptive" care makes intu- itive sense. Indeed, even though no significant effect was seen on the measured outcomes, hospitals involved in the study have generally refused to disband the MET system. The results of this trial suggest, however, that further investigation is required before METs are widely adopted.

Dominique Piquette

Department of Critical Care Medicine
Robert A. Fowler

Division of General Internal

Medicine

Interdepartmental Division of

Critical Care Medicine

Sunnybrook and Women's College

Health Sciences Centre

Toronto, Ont.

\section{Reference}

1. Scales DC, Abrahamson S, Brunet F, Fowler R, Costello J, Granton JT, et al. The ICU outreach team. 7 Crit Care 2003;18:95-106.
THE FRAMEWORK

\section{for HIGH STANDARDS and DEDICATION}

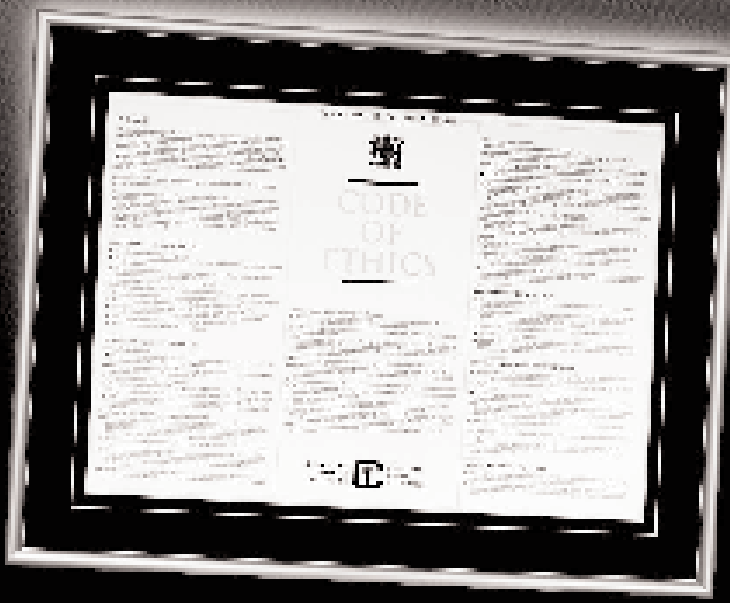

Patients rby an you for your expertive, ompesionard integribr.

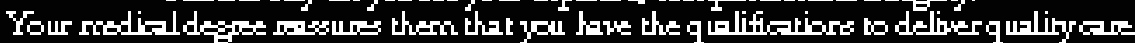
Bydieployire the CMLA Code of Ethis you will $\mathrm{Provide}$ them with the added confidence

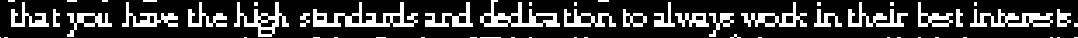

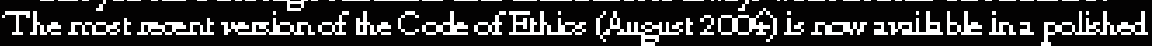
siber fome with a denim matte acent for you bo poudby diphy or b neocginas a oollogute for their ommitment and medial portesibralima
CAHAD LAN IA EDLCAL ASOOCLATLN

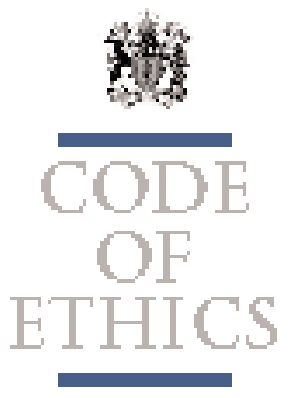

Wougr p be jo ur oodec by vele ghore throusth the Clive Member Service Centre at $1888855-2555$

o ronline 가

cma.ca' cmaboolsthtm Online odecinsis zuible bo vecier ed ues of oman vecistation is fire to Ceradian p thysicins and onty alcs 2 minut.

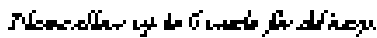

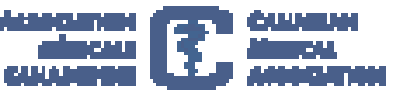

